\title{
Memory for surnames
}

\author{
JOHN F. HALL \\ Pennsylvania State University, University Park, Pennsylvania 16802
}

\begin{abstract}
Two experiments were undertaken to examine if surnames and words that were orthographically identical differed in terms of (1) association value and pronounceableness and (2) characteristic associative structure. A third experiment examined free recall for these two types of materials. Results indicated that surnames and words were equally easy (or difficult) to pronounce and did not differ in rated number of associations. Free association responses to both types of items suggested that surnames were responded to as words. Lists of these items, identified as either surnames or words, were recalled with equal facility.
\end{abstract}

At the turn of the century, William James (1890) wrote that proper names were harder to remember than those of general properties and classes of things. Our memory for surnames appears to be an appropriate example of James' position, since many of us have difficulty in remembering this type of material. Surprisingly, few studies of surnames have been made, although professional mnemonists have described several techniques designed to enable their readers to recall surnames (e.g., Lorayne \& Lucas, 1974; Roth, 1959). Current experimental interest in surnames has been largely confined to an examination of the association of names with faces (e.g., Bahrick, Bahrick, \& Wittlinger, 1975; Read \& Wilbur, 1975; Yarmey, 1973).

One hypothesis for explaining the difficulty of surname recall would be that surnames are generally of lower objective frequency than other to-be-recalled verbal items. Numerous studies have demonstrated that objective frequency, as measured by the ThorndikeLorge (1944) frequency count, does play an important role in memory (e.g., Bousfield \& Cohen, 1955; Hall, 1954; Underwood, Ekstrand, \& Keppel, 1965). But it is possible that surnames possess some other characteristic or result in a particular memorial process that contributes to an accelerated memory loss for this type of material. Perhaps the individual establishes a different (less elaborate?) associative network for surnames than for other kinds of verbal material.

One approach to the study of surnames would be to determine how (1) verbal attributes, (2) associative structure, and (3) memory for surnames compare with words when both kinds of experimental material are orthographically the same.

\section{EXPERIMENT 1}

Experiment 1 examined how the verbal material attributes of (1) association value and (2) pronounceableness compare when the experimental material consists of surnames and words that are orthographically identical.

\section{Method}

Materials. Forty five-, six-, or seven-letter words were selected from Thorndike and Lorge (1944) and served as the basic experimental material on which association value and pronounceability ratings were to be obtained. These words covered a broad range of frequencies (1 to AA). A requirement for inclusion in the list was that these words could be found as surnames in a current Philadelphia telephone directory.

Two 7-point rating scales were constructed to measure: (1) number of associations and (2) pronounceableness. The surname rating scales had the 40 experimental items mixed with 30 additional surnames, none of which were words. It was believed that the presence of these 30 readily identifiable surnames would enhance the subject's identification of the 40 experimental items as surnames. In addition, the instructions provided on each surname rating scale identified the items as surnames, and several examples were used to illustrate the rating procedure.

The association and pronounceability rating scales for words combined the 40 experimental items with 30 other words selected from Thorndike and Lorge (1944). Instructions provided on each rating scale identified the items as words, and several examples were used to illustrate the rating procedure.

Subjects. Fifty subjects were recruited from introductory psychology classes. Twenty-six subjects, randomly selected from the 50 , were administered the surname rating scales, whereas 24 subjects were administered the common word scales. Half of each group rated the items on the association scale first, whereas the other half rated the items on the pronounceableness scale first.

\section{Results}

Only the 40 experimental items on each scale were analyzed, with ratings obtained for all 2,000 items. Means for the association value and pronounceableness of each word and surname were first obtained, after which overall means for the 40 words and the 40 surnames were obtained. The mean association value for the words was 4.49 , and that for surnames was 4.22 . For pronounceability means, the corresponding values were 6.25 for words and 6.46 for surnames. Neither difference was statistically significant.

\section{EXPERIMENT 2}

The association rating scale used in Experiment 1 revealed only a numerical value for each surname. But 
what would be the nature of the specific free association to a surname (1) when the surname was a word and (2) when the name was a nonword? Experiment 2 was designed to answer this question.

\section{Method}

Materials. For the surname-word group, 20 items were randomly selected from the previously used 40 experimental items. A single free association response was obtained from each of these 20 items. All items were identified to the experimental subjects as surnames. This was done by using $3 \times 5$ in. cards on each of which the abbreviation Mr./Ms. had been placed, followed by the name and then a blank line on which subjects were instructed to write in the first word that they associated with that name.

For the surname-nonword group, 20 names that were not words and that had been used as "filler" items in the surname rating scales in Experiment 1 served as the experimental material. Some of these names could be described as having been previously encountered (e.g., Davis, Nelson, etc.), whereas other names would be only rarely encountered (e.g., Preski, Zanis). Each name was placed on a $3 \times 5$ in. card, prefixed by a Mr./Ms., and subjects were asked to write in the first word that they associated with that surname.

Subjects. Twenty-four subjects obtained from an introductory experimental laboratory class served as subjects. The surnameword group comprised 14 subjects who were asked to provide free associations to the words that were identified as surnames. Ten subjects served in the surname-nonword group and provided free associations to the nonword surnames.

\section{Results}

Words as surnames. Of 280 possible responses for the 14 subjects to 20 words identified as surnames, there were only 9 instances in which the subject failed to respond, a response failure of approximately $3 \%$. Of the 271 responses provided, 14 of these (about 5\%) could be identified as being associated with the stimulus item that was perceived as a surname. In some instances, responses were obviously idiosyncratic to the responder; in other cases, the responses were other names commonly associated with the stimulus name (e.g., "Child" eliciting "Julia," "Swift" eliciting "Jonathan," etc.). With almost 95\% of the responses, however, a surname was responded to as being a word (e.g., "Hammer" eliciting "nail," "Hand" eliciting "foot," etc.).

Nonwords as surnames. Of 200 possible responses for the 10 subjects to the 20 proper names, there were 82 instances in which the subject did not respond, a response failure of $41 \%$. This finding is in keeping with the findings of Hall and Ugelow (1957), who noted that blocking or not responding frequently takes place when low-frequency words are used as the experimental material. Most of the proper names used would undoubtedly be classified as very low frequency.

The basic response data consisted of 118 free association responses, and a descriptive analysis of these responses suggests that they were of two general types. In those instances in which it could be assumed that the subject had encountered the surname from time to time, the response was typically an associate of the name (e.g., "Nelson" would elicit "Rockefeller," etc.). The second type of response could be characterized as being elicited by the visual or auditory characteristics of the word (e.g., "Tissian" elicited "Russian" or "tissue," "Feaster" elicited "feast," "faster," etc.).

\section{EXPERIMENT 3}

Experiment 3 consisted of an examination of memory for items when they were identified as either (1) words or (2) surnames.

\section{Method}

Materials. The 40 words used in Experiment 1 served as the material to be learned, with each item placed on a separate $3 \times 5$ in. card. The written instructions provided to the subjects in Group 1 indicated that they had just pledged a sorority or fraternity and that the name placed on each card was a member of that group. Their task was to memorize as many of the names as they could. The written instructions provided to Group 2 indicated that they were subjects in a memory experiment and their task was to memorize as many of the words as they could. Both groups were instructed to go through the list of items at their own speed, but not to spend too much time on any one item. When they were finished, they were given a sheet of paper on which they were to write down as many of the items as they could remember. A maximum of 5 min was provided for completion of the task.

Subjects. Forty-three subjects served in Group 1; 38 subjects served in Group 2. All subjects were recruited from introductory psychology classes and were randomly assigned to each group. Subjects were run in groups of three, four, or five.

\section{Results}

The results revealed no difference between the experimental items when they were identified as surnames or as words. The mean number of surnames recalled was 19.3 , whereas the mean number of words recalled was 19.5.

\section{DISCUSSION}

There is no evidence to support the position that a surname, when orthographically identical to a word, is represented by a unique node in memory or that its associative network differs from that of the common word. Subjects report that surnames and words are equally easy (or difficult) to pronounce, and there appears to be no difference in the number of associations elicited by each type of stimulus item. The examination of free association responses to both types of stimulus materials suggests also that surnames are responded to as words. If the surnames are not found in the lexicon, the associations that are elicited by them mirror the kinds of associations that are found to rare words. Finally, lists of identical items, but identified either as surnames or as words, are recalled with equal facility.

Words and surnames that are orthographically identical do not appear to differ with regard to their verbal attributes or their recallability. Moreover, those surnames that are not words and are only infrequently encountered appear to have the associative characteristics of rare or low-frequency words. This evidence suggests that a basic reason that individuals have difficulty in remembering surnames can be attributed to the fact that surnames simply do not have the same objective frequency as other to-be-recalled words. Additional support for this position can be found by examining the objective frequency 
of proper names found in Thorndike and Lorge (1944). A count of all of the high-frequency (A and AA) proper names totaled only 63 , with "Smith" being the only characteristic surname having high frequency. The remaining high-frequency proper names, with few exceptions, could be identified primarily as (1) locations or nationalities (e.g., America, Boston, Europe, France, etc.), (2) first names (or nicknames) (e.g., Dick, Harry, Henry, Jim, etc.), (3) days of the week (e.g., Saturday, Sunday, etc.), or (4) months of the year (e.g., January, February, etc.).

The transformation of objective frequency into a psychological variable is necessary in order to better understand why a list of high-frequency words is better recalled than a list of low-frequency words. Deese's (1960) suggestion that objective frequency can be related to interitem associative strength may be a useful point of departure for future research efforts.

\section{REFERENCES}

Bahrick, H. P., Bahrick, P. O., \& Wittlinger, R. P. Fifty years of memory for names and faces: A cross-sectional approach. Journal of Experimental Psychology: General, 1975, 104, 54-75.

Bousfield, W. A., \& Cohen, B. H. The occurrence of clustering in the recall of randomly arranged words of different frequencies of usage. Journal of General Psychology, 1955, 52, 83-95.
DEESE, J. Frequency of usage and number of words in free recall: The role of associations. Psychological Reports, 1960, 7, 337-344.

Hall, J. F. Learning as a function of word-frequency. American Journal of Psychology, 1954, 67, 138-140.

Hall, J. F., \& Ugelow, A. Free association time as a function of word frequency. Canadian Journal of Psychology, 1957, 11, 29-32.

James, W. Principles of psychology. New York: Holt, Rinehart \& Winston, 1890.

Lorayne, H., \& Lucas, J. The memory book. New York: Stein \& Day, 1974.

READ, J. D., \& Wilbur, R. G. Availability of faces and names in recall. Perceptual and Motor Skills, 1975, 41, 263-270.

Rotн, D. M. Roth memory course. Cleveland, Ohio: Ralston, 1959.

Thorndike, E. L., \& Lorge, I. The teacher's word book of 30,000 words. New York: Columbia University Press, 1944.

Underwood, B. J., Ekstrand, B. R., \& KePpel, G. An analysis of intra-list similarity in verbal learning with experiments on conceptual similarity. Journal of Verbal Learning and Verbal Behavior, 1965, 4, 447-462.

YARMEY, A. D. I recognize your face but I can't remember your name: Further evidence on the tip-of-the-tongue phenomenon. Memory \& Cognition, 1973, 1, 287-290.

(Received for publication March 23, 1982.) 